\title{
What to Take Away from Sellars's Kantian Naturalism
}

\author{
James R. O'Shea, University College Dublin
}

(This is the author's post-peer reviewed version. For citations, please refer to the published version in: James R. O'Shea, ed., Sellars and His Legacy, Oxford: Oxford University Press, 2016, pp. 130-148.)

\begin{abstract}
I contend that Sellars defends a uniquely Kantian naturalist outlook both in general and more particularly in relation to the nature and status of what he calls 'epistemic principles'; and I attempt to show that this remains a plausible and distinctive position even when detached from Sellars's quasi-Kantian transcendental idealist contention that the perceptible objects of the manifest image strictly speaking do not exist, i.e., as conceived within that common sense framework. I first explain the complex Kant-inspired sense in which Sellars did not take the latter thesis concerning the objects of the manifest image to apply, at least in certain fundamental respects, to persons. In this primary Kantian sense, I suggest, persons as thinkers and agents exist univocally across both the manifest and scientific images, and this in principle would enable an integration of persons within a multi-leveled naturalistic ontology, one that is independent of Sellars's quasi-Kantian transcendental idealist thesis. Finally, I examine in some detail how this defensible blend of Kantian and naturalist themes turns out to be what is fundamental in Sellars's complex and controversial views on the nature and status of epistemic principles.
\end{abstract}

KEYWORDS: Sellars, Kant, naturalism, transcendental idealism, epistemic principles, persons, manifest image, scientific image, perception.

\section{Introduction}

I contend that there is a distinctive and defensible Kantian naturalist line of thinking running throughout Sellars's philosophy that remains highly promising despite (a) its having been overshadowed by certain stronger, more disputable contentions with which it was essentially connected in Sellars's thought, and (b) its having been largely lost in the legacy that has subsequently divided so-called 'left wing' (Hegelian, pragmatist, Wittgensteinian) Sellarsians from 'right wing' scientific naturalist Sellarsians. ${ }^{1}$ The central and itself controversial line of thought is that fundamentally Kantian conceptions of our cognition and agency can be integrated successfully with certain scientific naturalist philosophical outlooks that are usually taken to be incompatible with those Kantian views. Here I will focus on what Sellars called epistemic principles. In what follows I first attempt to detach Sellars's subtle Kantian naturalism from the most well-known, quasi-Kantian banner under which Sellars himself flew it: namely, his contention that, all things considered and strictly speaking, the object-ontology ${ }^{2}$ of "the common sense framework" - that

\footnotetext{
${ }^{1}$ See the Introduction to this volume for the background context of Sellars's diverse legacy.

2 As we shall see below, there turns out to be an important sense in which for Sellars, as for Kant, persons are in certain crucial respects not 'objects' in such a way as to render them candidates for replacement by
} 
is, the "manifest image" conception of perceptible, colored physical objects - "is transcendentally ideal, i.e. that there really are no such things as the objects of which it speaks" (SM V, $\$ 95$; italics added).

Of course in another sense, on Sellars's view, the perceptible objects of the manifest image do really exist: namely, as they are or will be analogically reconceived in their more adequate scientific successor concepts (cf. SM V). There are many other points that could and should be made about the complex relationships between the manifest and scientific images, on Sellars's view, that would lessen the initial shock to common sense of his striking contention concerning the ultimate replacement of the object-ontology of the manifest image. But this is not my aim on the present occasion, which is rather to display the largely overlooked plausibility of Sellars's innovative Kantian naturalist outlook, as I characterize it, even when this is detached from the more controversial quasi-Kantian contention that strictly speaking - and about this 'strict' sense much more would need to be said ${ }^{3}$ - "there are no such things as the colored physical objects of the common-sense world” (EPM IX, \41).

I call the latter striking contention 'quasi-Kantian' in part for the obvious reason that Sellars's own proposal, in effect, was to replace Kant's thinkable but unknowable 'things in themselves' or 'noumena' with the postulated and (at the manifest level) imperceptible yet eminently knowable objects of ongoing scientific theorizing. In addition to this there are also longstanding controversies concerning the nature of Kant's transcendental idealism itself, and while in my own work on Kant's philosophy I am heavily influenced by the interpretations of Kant defended by Sellars and by his student (and my teacher) Jay Rosenberg, on the specific interpretive question of Kant's own understanding of our inevitable and 'problematic' thought of the existence of so-called 'things in themselves' I am inclined toward the more deflationary, epistemic readings of this aspect of Kant's thought (though I shall not engage that interpretive controversy on this occasion). ${ }^{4}$ For my present purposes, I will begin with a closer look at Sellars's striking ontological

more adequate scientific successor conceptions of their nature. This is compatible with there also being many other aspects of persons and their bodies that are subject to such explanatory reconceptions in the ongoing development of the scientific image.

${ }^{3}$ I examine Sellars's complex views on conceptual change and replacement ontologies in relation to his envisioned final synoptic "fusion" of the manifest and scientific images of "man-in-the-world," in chapters 6 and 7 of my Wilfrid Sellars: Naturalism with a Normative Turn (2007). A first pass at some of the topics discussed in this chapter may be found in O'Shea (2011), which was my reply to some helpful objections to my reading of Sellars offered by William Rottschaefer in the same journal issue (along with his further reply).

${ }^{4}$ For an extended defense of Sellars's interpretation and development of Kant's transcendental idealism, see Sicha 2002, in Sellars (KTM). For my own interpretation of Kant's views, see O'Shea (2012a), Kant's Critique of Pure Reason: An Introduction and Interpretation. (On the role of 'things in themselves' in particular, see the various references in the index of that work under 'idealism: transcendental'.) For Jay Rosenberg's outstanding and thoroughly Sellarsian introduction to Kant's first Critique, see Rosenberg 2005. Where I differ from Rosenberg primarily concerns what is, in effect, his attribution to Kant (2005: 79-81) of Sellars's analogical theory of sense impressions, where this is understood as a theory of the ultimate counterparts, obtaining among 'things as they are in themselves', to the phenomenal spatiotemporal relations among objects that we cognize in experience. Sellars was generally circumspect about attributing these particular Sellarsian views to Kant himself, holding rather that this is what Kant ought to have thought given the full implications of his view (cf. Sellars SM, chapters 1-2; and KTE, the first footnote, on "Kant's treatment of sensation" as "notoriously inadequate and inept"). But the overall strongly ontological interpretation of Kant's 'things in themselves' is shared by Rosenberg and Sellars. My 2012 book inclines toward well-known alternative, non-traditional readings of Kant's transcendental idealism, but is otherwise compatible with Sellars's insightful accounts of Kant's conceptions of cognition and agency. See also David Landy (2015) for a very interesting Sellarsian reading of Kant on the analogical role of non-conceptual sensations in 
contention and its relationship to his reading of Kant. This will then pave the way for an examination of those genuinely Kantian yet also consistently naturalistic aspects of Sellars's thoughts about the structure of human knowledge that I want to highlight and defend here.

Overall, then, I will argue that in a primary Kantian sense persons as thinkers and agents exist univocally across both the manifest and scientific images, and that this in principle would enable an integration of persons within a multi-leveled naturalistic ontology that is independent of Sellars's quasi-Kantian transcendental idealist thesis that the objects of the manifest image do not exist per se. Finally, I examine how this defensible blend of Kantian and naturalist themes turns out to be what is really fundamental in Sellars's view of the nature and status of epistemic principles in general.

\section{Sellars's Quasi-Kantian Transcendental Idealism: Color, Ultimate Homogeneity, and Relocation}

Readers of Kant and Sellars sometimes overlook the fact that in chapter two of Science and Metaphysics Sellars rejected Kant's own arguments for transcendental idealism as fallacious, both with respect to space and time and in relation to the categories (SM II, $\iint 58-78$ ). Sellars's own proposal is the following:

Kant...failed to notice a further line of argument for the transcendental ideality of perceptible things which really works, and is the one I shall espouse. [Footnote:] I shall tip my hand by saying that the true ground for the transcendental ideality of the perceptual world lies in the distinction between perceptible physical objects and the objects of theoretical science, a distinction which was blurred by Kant. (SM II, \$69)

The feature of perceptible physical objects upon which Sellars proceeds to focus in this context is their color, the discussion of which he sums up as follows:

Thus Kant should have recognized that colour...is as essential a feature of the objects of outer intuition as is shape. If, therefore, a sound case can be made for the idea that the colours we conceptually represent in perception are transcendentally ideal, i.e. exist only as conceptually represented, then it would follow that the world of perceived objects is, after all, in the Kantian sense, 'appearance'. [Footnote:] Notice that this is, of course, compatible with the idea that certain counterpart attributes, conceived by analogy with them, are transcendentally real, though, perhaps, only as in some sense states of the perceiver. (SM II, \$75)

We need not rehearse here Sellars's various arguments in relation to the supposed 'ultimate homogeneity' of perceived expanses of color in contrast (initially) to the particulate objects of the emerging scientific image, and his further contention that this necessitates the reconception and ontological 'relocation' (so to speak) of homogeneous color contents from being sensible qualities of physical objects to being states of perceivers, followed by further such explanatory reconceptions in line with Sellars's projected 'pure process' ontology. ${ }^{5}$ But broadly speaking, as

cognition, but interpreted by Landy as a view within Kant's empirical realism rather than (as in Sellars) concerning 'things in themselves'.

${ }^{5}$ One locus classicus for these topics is Sellars, see PSIM V-VI; another is FMPP, passim. A thoroughgoing and richly suggestive defense of Sellars's views on these topics may be found in Seibt, chapter 9 of this 
indicated in the passage above, Sellars on these grounds held that a proper respect for Berkeley's insight concerning the inseparability of perceived color and shape, among other considerations, ultimately entails the striking contention above concerning the ultimate falsity, strictly speaking, of the common sense framework of perceptible physical objects. It is this quasi-Kantian replacement for Kant's transcendental idealism that for present purposes I want to detach from certain other deeply Kantian views in Sellars that I suggest can survive the excision.

I need to make two further important observations about Sellars's quasi-Kantian übercontention before moving beyond it for present purposes.

First, when Sellars indicates that he regards the objects of the manifest image to be 'transcendentally ideal' or 'phenomenal' or 'appearances', in his (and allegedly Kant's) sense that strictly speaking such objects do not exist per se, he means carefully to distinguish this from any claim about persons and norms, along with the attendant dimensions of meaning, truth, and intentionality that the latter entail. For Sellars argues that persons and norms as conceived within the manifest image can be integrated successfully in one "stereoscopic" and "synoptic vision" with the ideal scientific ontology that he argues must replace the perceptible objects of the framework of common sense (cf. PSIM VI-VII). My suggestion is that the modified Kantian arguments that Sellars puts forward in this connection can be combined with various naturalistic hypotheses in Sellars, often taken to be incompatible with them, that do not require Sellars's further striking contention that the perceptible objects of common sense do not strictly speaking exist. The remaining 'Kantian naturalist' outlook, whatever its ultimate merits, was a distinctive twentieth century philosophical contribution from Sellars - one which, even when detached from the more striking but widely rejected quasi-Kantian framework in which Sellars embedded it, represented a unique combination of philosophical aspirations that should distinguish it from the valuable contributions of other 'analytic Kantians' who have subsequently followed in the wake of the later Wittgenstein and P. F. Strawson.

Second, there is nothing in the rejection of Sellars's arguments for his über-contention concerning the object-ontology of the common sense framework that requires us also to reject scientific realism with respect to unobservable theoretical objects, in contrast with instrumentalist or constructive empiricist views, etc., in the philosophy of science. Scientific realism in this basic sense is now widely accepted, in part due to Sellars's own important mid-century criticisms of instrumentalist conceptions of the nature of scientific explanation. For my purposes what would have to be argued against in relation to Sellars's wider views on this matter is the alleged incompatibility of that scientific realist outlook with the 'manifest' ontology of colored physical objects. The falsity of that incompatibility claim will be presupposed rather than argued for here, despite its admittedly central role in Sellars's philosophy. The question of just which aspects of Sellars's complex views on the nature of sense perception and sensory consciousness can and should survive the rejection of the particular arguments concerning sensible qualities that service Sellars's incompatibility claim is an important one that I have investigated elsewhere (O'Shea 2010; see also David Rosenthal, chapter 8 this volume).

\section{Sellars and Kant on Knowledge, Nature, and the Thinking Self}

volume. For a systematic and plausible defense of key aspects of Sellars's views on sensory consciousness that nonetheless diagnoses and rejects the 'relocation' story, see Rosenthal, chapter 8 of this volume; and also along these general lines see the in-depth defence of a Sellarsian critical realist theory of sense perception in Coates (2007). The relationships between Sellars's and Kant's views on sensibility and perceptual cognition are also explored in some depth, and with insight, in Haag 2012. 
It is clear from his 'Autobiographical Reflections' that Sellars viewed his own philosophical development from very early on as an evolving attempt to harmonize two deeply held philosophical convictions (cf. the Introduction to this volume). The first was that Kant was in certain crucial respects fundamentally correct about the a priori necessary structure of human knowledge and rational agency. This first conviction would later find one expression in Sellars's famous remark in 'Empiricism and the Philosophy of Mind' that "in characterizing an episode or a state as that of knowing, we are not giving an empirical description of that episode or state; we are placing it in the logical space of reasons, of justifying and being able to justify what one says" (EPM VIII, \$36). The second enduring conviction, however, was that this Kantian normative structure would itself somehow have to be fully explainable in principle within a comprehensively scientific naturalist ontology. Sellars reassured the logical empiricist Herbert Feigl in the 1930's, for example, that they "shared a common purpose: to formulate a scientifically oriented, naturalistic realism which would 'save the appearances'," in relation to which Sellars further clarified that for him, although not for Feigl, the "aim was to map these structures" - that is, "such ideas as causal necessity, synthetic a priori knowledge, intentionality, ethical intuitionism, the problem of universals, etc." - "into a naturalistic, even a materialistic, metaphysics" (AR 290). What Sellars then proceeded to argue throughout his career, not without some historical irony, is that it is the essential truth of Kant's views concerning the a priori conceptual structure of our thought and experience that in fact provides the only satisfactory way for us to go beyond Kant and successfully envision the standpoint of a fully comprehensive or 'synoptic' naturalism.

As noted in the Introduction, it is this enduring twofold project of Sellars's - that of defending a Kantian conception of our conceptual cognition, and yet at the same time attempting to sketch how to naturalize that same conception - that I think has been the primary source of the subsequent forks in the road that have been carved out by those who have been strongly influenced by Sellars's work. My concern here is not with either the nature or the genesis of the distinction between the subsequent 'left wing' Sellarsians who emphasize the irreducibly normative Kantian aspects of Sellars's view, and the 'right wing' Sellarsians who seek to realize Sellars's ambitiously naturalistic aims, but rather to explore some of the ways in which Sellars thought it might make sense to be both a Kantian and a naturalist about the structure of our knowledge. I believe that the fulcrum of Sellars's simultaneously Kantian yet naturalist conception of our knowledge is his self-consciously Kantian conception of the nature of the human knower or thinker, although this topic is not typically explored in discussions of Sellars's epistemology and metaphysics.

Sellars argued that there are insights in Kant's conception of the thinking self that make possible a stronger integration of Kantian views with a naturalistic ontology than Kant himself was either willing or able to attempt. Furthermore, and most usefully for my purposes, Sellars maintained that this particular integration holds across both the Aristotelian/Strawsonian ontology of persons and their bodies that characterizes Sellars's manifest image ontology (the "commonsense framework") and in the case of the revisionary object-ontology of Sellars's envisioned scientific image according to which, in the end, a "person would be a bundle of absolute processes" (FMPP III, \$125). The place where Sellars sketched this view most helpfully was in his 1970 APA Presidential Address, entitled “... This I or He or It (the Thing) Which Thinks..." ('I'; see also his 'Metaphysics and the Concept of a Person' (MP)).

"In the manifest image," Sellars holds, "our concept of a person" is "that of a system of capacities pertaining to the various modes of thinking" (MP V, \$57), where such "modes of thinking' on Sellars's account include our perceptions and volitions, too. While we cannot explore the details of this account here, in 'This I...' Sellars offers an interpretation of Kant on the unity of apperception that begins with 
an unrestricted principle in the philosophy of mind, which transcends the distinction between the noumenal and the phenomenal self, to the effect that

an I thinks of a manifold

is not to be confused with

an I has a manifold of thoughts. ('I' \$7)

Furthermore, the "ways in which many thinkings constitute one thinking are the "forms of thought', e.g. the categories" ('I' $\$ 8$ ). This unrestricted principle concerning the conceived unity of the thinker and a correlative unity in the form of its thinkable thoughts is then argued by Sellars (interpreting Kant) to entail the more specific, holistic

epistemic principle that any true content of thought, e.g., that Socrates is wise, must, in principle, be an element in a certain kind of larger context, e.g.,

an I thinks the true thought of a world in which Socrates is wise.

Roughly, the form of empirical knowledge is: an I thinking (however schematically) the thought of a temporal system of states of affairs to which any actual state of affairs belongs. ('I' $\int 9$; italics added)

In Kant, the correlative "synthetic unity of apperception" roughly takes the form of an "I thinking a complex spatial-temporal-causal system of states of affairs..." ('I' \$10) within which any particular perceived state of affairs must be lawfully integrated in general.

My understanding of Sellars is that he takes these Kantian claims to be defensible in general across both the manifest and scientific images of 'man-in-the-world', albeit as appropriately modified to reflect the later 'linguistic turn' or 'new way of words' in philosophy. In fact this is the key to his own "synoptic vision" of the stereoscopic unity of those two idealized images, in which the manifest image conception of persons as thinking and intending beings is supposed to be preserved rather than "overwhelmed” (PSIM II 923, ISR 377, SPR 8-9). Importantly for my present purposes, much of the remainder of Sellars's 'This I...' article in fact contains some subtle suggestions, building on Kant's analysis in the 'Paralogisms' chapter of the Critique of Pure Reason, as to how those Kantian truths can and should be modified in such a way as to accommodate a broadly Strawsonian or manifest image conception of knowable embodied persons that Kant himself officially rejects (for various reasons that Sellars explores), and which would be consistent with a naturalistic ontology at least in the following way:

(1) that the empirical self - the I which we experience as thinking in time - is an aspect of a perceptible object which, as having physical attributes, is a body (i.e. that the logical subject which, as representing and capable of representing, is a being which thinks is identical with the being which, as having material attributes, is the body);

(2) that the empirical I which, in so far forth as it is represented as thinking, is not represented as composite, is nevertheless identical with (i.e. is) a composite physical object. ('I’ $\$ 30)$ 
For what Sellars endorses from Kant's analysis in the Paralogisms is that a unitary "logical subject" of thoughts "which is not represented as an aspect of something more basic" or "as composite" nevertheless "may be an aspect of something more basic" or "be composite" (I' \$31). It is important to note that for Sellars the sense of "more basic" here would not require us "to say that my knowledge of myself as logically identical through the period of time in question is an illusion, but only that the logical identity of the I as I represent it, is not an adequate conceptualization of 'the nature of our thinking being" " 'I' \$28). That is, the more "adequate conceptualization" of the nature of our thinking being, pace Kant (Sellars argues), can and should add to that formal or transcendental knowledge of the self the further knowledge that is contained in passages (1) and (2) above ('I' \$30). The upshot is that Sellars has here attempted to defend the conceptual irreducibility and "logical identity" of the thinking self in a way that is compatible with a thoroughgoing naturalistic ontology of the self, and that this is the case, according to Sellars's own reckoning, whether the self is realized in the conceptual capacities of a manifest perceptible material substance or, as on Sellars's own ultimate object-ontology, in what is ultimately "a bundle of absolute processes” (FMPP III, \$125). This striking Kantian naturalist outlook animated from start to finish Sellars's philosophical vision of 'how things hang together' - and in particular, how normativity, personhood, conceptual thinking, and knowledge are preserved - across the manifest and scientific images, as is illustrated by the following remark on Kant from Sellars's posthumously published Notre Dame lectures: "When I talk about the in principle replaceability of the manifest image by the scientific image, I do so with respect to the content of the world, its material and not with respect to those forms which concern the normative, the obligatory, the correct, the incorrect, the valuable .... I think Kant is essentially right, not only in many of the things he said in a theory of knowledge but also in ethics" (WSNDL, pp. 223-4). Or more particularly as Sellars summed up his Kantian naturalist conception of persons in his 'Phenomenalism' article:

The heart of the matter is the fact that the irreducibility of the 'I' within the framework of first person discourse ... is compatible with the thesis that persons can (in principle) be exhaustively described in terms which involve no reference to such an irreducible subject. For the description will mention rather than use the framework to which these logical subjects belong. Kant saw that the transcendental unity of apperception is a form of experience rather than a disclosure of ultimate reality. If persons are 'really' multiplicities of logical subjects, then unless these multiplicities used the conceptual framework of persons there would be no persons. But the idea that persons 'really are' such multiplicities does not require that concepts pertaining to persons be analysable into concepts pertaining to sets of logical subjects. Persons may 'really be' bundles, but the concept of a person is not the concept of a bundle. (PHM III, $\mid 45,101$ )

Obviously the above account has only scratched the surface of what I have been suggesting is Sellars's Kantian naturalist view of the nature of the thinking self together with the correlative Kantian conception of an "epistemic principle" that is supposed to encapsulate the necessarily holistic and systematic structure within which any particular item of knowledge must find its place. (For further exploration, I recommend Jay Rosenberg's unjustly neglected Kantian and Sellarsian book, The Thinking Self (1986), recently reissued by Ridgeview.) Sellars held that Kant justified his synthetic a priori (meta-) principles by embedding them within what is ultimately an analysis of the conceptually necessary conditions on any conceptual representation of temporal states-of-affairs in a world (cf. KTE $\$ \$ 10-11)$. In what follows I will argue that for Sellars the above Kantian naturalist framework also provided the basis for his own more detailed accounts, extending throughout his career, of the epistemic principles that he contends are necessary for the possibility of our knowledge of objective states of affairs - or more basically, for the possibility of our having any empirically contentful thought about objective states of affairs in the first place. 


\section{Sellars on Perceptual Knowledge and Epistemic Principles}

Let us consider as our specimen for further examination Sellars's account of human perceptual knowledge. As briefly noted in the Introduction to this volume, at a minimum, and assuming familiarity with Sellars's dot-quotation device (the dot quotes, roughly speaking, indicate normative-functional conceptual role or 'use' classifications), a typical adult, human visual perception of a red physical object, for Sellars, is contituted by:

(a) a conceptually contentful, rule-governed response [roughly, an $\bullet x$ is red $\bullet$ thought],

(b) normally caused by the appropriate corresponding object [i.e., by red objects], and

(c) causally (not epistemically) mediated by nonconceptual sensings [sensing red-ly].

The conceptual component in (a), on Sellars's account, entails that the perceptual knower must possess whatever conceptual capacities are necessary for one's thoughts and responses to have a place "in the logical space of reasons, of justifying and being able to justify what one says" (EPM VIII, (36). We shall see that just what this requirement entails is a matter of controversy. The causal dimension in (b), on Sellars's view, amounts to a normatively constituted and constrained reliability condition on perceptual knowledge. Paradigmatically, in the case of adult human conceptual responses, the relevant norms that generate the reliability required of our perceptual knowings, on Sellars's view, derive from the 'ought-to-be's and correlative 'ought-to-do's that characterize our initiation into a living natural language: roughly put, it ought-to-be that children's responses (for example, 'That's red') and inferences ('So it's not green') come to reflect the normgoverned patterns of thought and behavior that constitute the relevant conceptual roles (opentextured and context dependent as they may be) within a given 'space of reasons'. Sellars holds compatibly with the above account of our reliable conceptualized perceptual responses - or so I and others have argued ${ }^{6}$ - that we also possess along with other animals more basic natural perceptual and active capacities the reliability of which is explainable in terms of inherited norms of functional adaptation that derive from our historical evolution by natural selection (see Sellars's MEV in particular, on "animal representational systems"). Our natural embedding within the latter biological patterns of normal functioning then partly accounts for the role in (c) of nonconceptual sensings in our perceptual knowings, the postulation of which is also required, Sellars argues, to explain the patterns of our conceptual responses in both veridical and non-veridical perceptual experiences (see, e.g., SM I, \44).

The distinctiveness of Sellars's subtly integrated Kantian and yet naturalist account of our sense-perceptual knowledge should be evident from the above sketch. In the other writings mentioned in the previous footnote I have been concerned to argue that Sellars's integration of a richly explanatory theory of nonconceptual sensings in (c) is not only compatible with his normative 'space of reasons' analysis of perceptual accountability in (a) (about which more below), but has much to recommend it as a cognitive-scientific empirical hypothesis worthy of further exploration. My particular concerns in what follows will be at the 'top level' of (a), so to speak, i.e., concerning Sellars's Kantian account of the source of justification for our reflectively responsible perceptual knowings. For Sellars's particular 'top-level' Kantian analysis of the necessary structure of our empirical knowledge has itself turned out to be as controversial among

${ }^{6}$ See, for example, Millikan, chapter 6 of this volume; O’Shea 2012b, 2010, and 2007 chapter 5; Rosenberg 1986, chapters 4-7; and Seibt, chapter 9 of this volume 
otherwise admiring Sellarsians as Sellars's 'bottom-level' attempt to embed a naturalistic theory of nonconceptual sensory representation within that conceptual analysis.

What view of knowledge did Sellars take to be embodied in the account of perception sketched above? The conceptual capacities and reasoning abilities in (a) of course reflect requirements on non-inferential knowledge that follow from Sellars's famous rejection of the myth of the given in EPM, the success of which I will presuppose here (cf. O'Shea 2007, chapter 5). Just what those requirements are, however, is a difficult and controversial matter on which Sellars continued to reflect in the decades following EPM, as we shall see. But on his view such requirements certainly require conceptual abilities sufficient for one's perceptual response to be a normative standing "in the logical space of reasons, of justifying and being able to justify what one says." It is also clear that on Sellars's view my perception of a red table in front of me is 'direct' or 'immediate' in at least two senses: first, due to the conceptualization involved in (a), the intentional object of my perceptual awareness is in this case the red physical object itself, not any postulated nonconceptual sensory representations as are involved in (c); and second, in being an object-evoked response as in (b) rather than the thought-evoked conclusion of an inference, the perceptual knowing is 'direct' or non-inferential in (at least) the sense of being evoked by its object rather than being inferred from another thought. So Sellars wants to defend a conception of our perceptual knowings that captures both their epistemic status as adequately justified and yet also their non-inferential directness or 'givenness', and to do so without falling back on the Myth of the Given.

In EPM in 1956 Sellars's basic proposal was that a perceiver S's belief that a given object is green, for example, is justified (or is a case of observational knowledge) only if (1) S's belief is the manifestation of a (reliable) tendency to form such beliefs, given a certain set, "if and only if a green object is being looked at in standard conditions" (EPM VIII \$35). But secondly, in addition to S's perceptual belief thus being in fact an extremely highly reliable indicator of the corresponding perceptible state of affairs, and thus possessing epistemic credibility or authority insofar as one can reliably infer the truth of the belief from the fact that $S$ forms it (in normal circumstances), Sellars also added the reflective condition that (2) "this authority must in some sense be recognized by the person whose report it is" (ibid.). ${ }^{7}$ Thus S in some sense has "to know that" her beliefs "of this kind are reliable indicators of the existence, suitably related to" her, "of green objects" (EPM VIII \$36). In particular, knowledge on Sellars's account requires that one be able, if called upon, to take responsibility for one's reliability, to be able to say something in support of one's assertional commitment if questions arise about the circumstances. In fact it was precisely in the context of the two paragraphs in EPM in which Sellars added this further reflective requirement on perceptual knowledge that Sellars made his now famous statement that "in characterizing an episode or state as that of knowing ... we are placing it in the logical space of reasons, of justifying and being able to justify what one says" (ibid.).

It is a direct consequence of this view that $\mathrm{S}$ must "in some sense" have knowledge of her own general reliability (in relation to cases of the relevant sort) if she is to have any particularperceptual knowledge whatsoever. Sellars trumpets this consequence as yet another reason to reject the sort of epistemic atomism that characterizes traditional foundationalist empiricism and the myth of the given (cf. EPM 532). The myth, in this respect, is that one could have knowledge of particular matters of fact in the absence of knowledge of certain general matters of fact - in this case the knowledge, "in some sense," of one's own general perceptual reliability in this kind of circumstance. But this virtue of the Sellarsian account also threatens to be its Achilles heel. For

${ }^{7}$ For insightful stress on the importance of reflexivity requirements throughout Sellars's philosophy, and on how this reflects insights of the German Idealist tradition from Kant to Hegel, see deVries 2005 and 2009. 
as Sellars recognized, this requirement immediately leads to the familiar challenge, on pain either of regress (EPM $\int S 36-7$ ) or of circularity ("More on Givenness and Explanatory Coherence,"

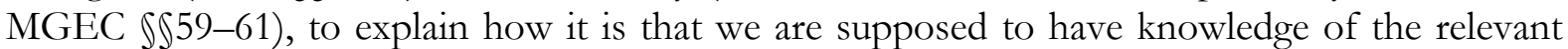
general epistemic principles or general matters of fact without relying on any knowledge of particular matters of fact (since the latter knowledge, ex bypothesi, is possible only if we already have a grip on the relevant general knowledge). Sellars addressed and re-addressed this difficulty across multiple writings throughout his career.

Sellars's continuing aim was to conceive how both of those dimensions of dependency can simultaneously be in play without this conception leading to implausibilities in either direction: neither resorting to conceiving direct perceptual knowledge in a way that threatens to reintroduce 'givenness' in any objectionable sense, nor demanding reflective inferential justification in a way that threatens to rob perceptual knowledge of such non-inferential warrant, in some sense, as it does seem to possess. That is, supposing that we have now rejected the myth of the given and have embraced both external reliability and reflective reason-giving as necessary for perceptual knowledge, this Sellarsian outlook needs to clarify how it is that our perceptual observations on the one hand are able to function as the sort of warranted non-inferential 'input' knowledge upon which our more general knowledge ordinarily depends, while on the other hand such items of knowledge are argued to be essentially dependent for their warranted status on a space of inferential patterns of justificatory reasoning that is "in some sense" already grasped by the perceiver.

In EPM Part VIII Sellars originally posed the problem in terms of a regress worry concerning knowledge acquisition. As we just saw, Sellars claims that $\mathrm{S}$ can perceptually know the particular fact that $\mathrm{P}$ only if $\mathrm{S}$ already knows some general fact about her reliability. The objection Sellars considers is that surely S's knowledge of her general reliability in that domain would have to be based upon at least some prior instances of S's having particular knowledge of facts in that domain. Sellars's response in EPM to what he called this "steep hurdle" (\$35) was to argue that the general knowledge of one's reliability that must be possessed by any responsible adult knower $\mathrm{S}$ can be based inductively on her present (non-inferential) memory of past facts (i.e., "Jones's ability to give inductive reasons today" (\$37)) concerning her having been trained into such reliable patterns of belief formation at a time when she was not then able to take reflective responsibility for her own general reliability: "And the regress disappears," Sellars concludes (EPM §37, including the footnote added in SPR in 1963). Sellars's sketchy idea here seems to be that we thus do not need to appeal to any mythically original instances of 'particular-without-general-knowledge' on S's part in order to understand how it is that her possession of any instance of particular knowledge does indeed require that she possess responsible general knowledge of her own reliability. She grew and was trained into her eventual possession of a sufficiently responsible grip on her own reliability through the social acquisition of the appropriate norm-guided habits of conceptuallinguistic response to objects and situations in appropriate circumstances.

The conclusion for Sellars in EPM was that the structure of reflectively responsible, reliable knowledge successfully exhibits both directions of dependency discussed above, an account which he famously summed up this way: ${ }^{8}$

There is clearly some point to the picture of human knowledge as resting on a level of propositions - observation reports - which do not rest on other propositions in the same way as other propositions rest on them. On the other hand, I do wish to insist that the

\footnotetext{
${ }^{8}$ John McDowell has stressed these two dimensions as central to what he appropriately characterizes as "Sellars's Transcendental Empiricism" (1999).
} 
metaphor of 'foundation' is misleading in that it keeps us from seeing that if there is a logical dimension in which other empirical propositions rest on observation reports, there is another logical dimension in which the latter rest on the former.

Above all, the picture is misleading because of its static character. One seems forced to choose between the picture of an elephant which rests on a tortoise (What supports the tortoise?) and the picture of a great Hegelian serpent of knowledge with its tail in its mouth (Where does it begin?). Neither will do. For empirical knowledge, like its sophisticated extension, science, is rational, not because it has a foundation but because it is a selfcorrecting enterprise which can put any claim in jeopardy, though not all at once. (EPM VIII \38)

This is essentially where Sellars left his account of the structure of our knowledge in EPM. However, it is clear from his subsequent writings that while he regarded the above conclusion to be sound in general, he also considered his own quasi-inductive response to the steep regress hurdle in EPM to be problematic.

In the third lecture of 'The Structure of Knowledge', entitled 'Epistemic Principles', Sellars argues (SK III, \$33) that "the justification involved in [such] 'non-inferential' knowledge" as when "Jones sees there to be a red apple in front of him" - provided that Jones has acquired a competent grip on the relevant concepts involved ${ }^{10}$ - consists in the fact that Jones is (if called upon) "justified in reasoning": I had the perceptual experience 'Here is a red apple' in normal circumstances (or as Sellars puts it, "no countervailing conditions obtain"); "So, there is good reason to believe that there is a red apple in front of me" (SK III, §33; italics added). Sellars comments:

Of course, the conclusion of this reasoning is not the thinking involved in his original perceptual experience. Like all justification arguments, it is a higher-order thinking. He did not originally infer that there is a red apple in front of him. Now, however, he is inferring from the character and context of his experience that it is veridical and that there is good reason to believe that there is indeed a red apple in front of him.

Notice that although the justification of the belief that there is a red apple in front of (Jones) is an inferential justification, it has the peculiar character that its essential premise asserts the occurrence of the very same belief in a specific context. It is this fact which gives the appearance that such beliefs are self-justifying and hence gives the justification the appearance of being non-inferential. (SK III, $\int \$ 34-35$ )

Sellars goes on to suggest that it is the latter misleading appearance that helps to explain the deep error of 'givennist' foundationalists such as Roderick Chisholm and all those who contend that in perception it is the fact that- $p$ that directly justifies one's non-inferential perceptual belief that-p. Or as Chisholm puts it (1966: 28, quoted by Sellars): "What justifies me in counting it as evident that $a$ is $F$ is simply the fact that $a$ is F." On Sellars's view above, by contrast, the justification takes the form (in light of the available reasoning above): "If I ostensibly see there to be an F object here, then it is highly reasonable for me (to believe) that there is an F object here" (SK III, \42). ${ }^{11}$

${ }^{9}$ For an insightful pragmatist stress on the importance of the diachronic second paragraph in this passage, see Michael Williams 2009.

10 As usual Sellars states all of this in terms of his "verbal behaviorist" (VB) linguistic model, but here I will assume the success of Sellars's 'myth of Jones' postulation of corresponding 'inner thought episodes' in EPM XV-XVI and SK I-II, and thus state matters in terms of thoughts and beliefs when convenient.

${ }^{11}$ Sellars's discussion of Chisholm at SK III, $\int \mathbb{S 3 6 - 4 2}$ is complicated by the fact that Chisholm's own principles, which Sellars here goes on to examine critically, are formulated in terms of Chisholm's view that 
In a footnote to the passage quoted above (SK III, \35) Sellars refers this "feature of the justification involved in 'non-inferential' knowledge" back to his earlier view in 'Phenomenalism' (PHM), written three years after EPM, that (and here he quotes himself) "to say that one directly knows that $-p$ is to say that his right to the conviction that- $p$ essentially involves the fact that the idea that- $p$ occurred to the knower in a specific way" (PHM V, $\mid 66,88$ ). He notes that in PHM he had called this "trans-level credibility," as involving a "trans-level inference" (cf. Jones's available higher-order thought and inference discussed above), and adds: "A similar point was less clearly made in Sections $\$ \$ 32-39$ of [EPM]." We have seen that the corresponding argument for a similar conclusion in EPM was made to turn on Jones's present ability to reason inductively about the fledgling nature of his past (originally unknowing) acquisition of the relevant conceptual abilities involved in being able to have the perceptual thought, 'Here is a red apple' (EPM \$37). Sellars's later epistemological writings such as SK and MGEC make clear, I suggest, that he came to regard as insufficient EPM's implausible appeal to "Jones's inductive reasons" as a response to the "steep hurdle" of having to account for Jones's non-circular knowledge of his general perceptual reliability, and thus for our knowledge of epistemic principles more generally. We shall also see that EPM \$38's important appeal to the "non-static" or diachronic character of "empirical knowledge" (or science) as a "self-correcting enterprise" is also regarded by Sellars as insufficient for clearing the steep hurdle of satisfactorily accounting for the nature of our non-circular, implicit knowledge of general epistemic principles. My contention is that Sellars's evolving solution to this problem involved clarifying more explicitly key aspects of his two-pronged Kantian naturalist approach both in its Kantian and in its scientific naturalist or broadly inductive explanatory dimensions.

In both SK and MGEC Sellars once again stressed the 'steep hurdle' in the form of a vicious circularity that threatens to obtain between our warranted general epistemic principles and the particular non-inferential perceptions they are supposed to warrant. In these articles, however, Sellars argues explicitly that it is a mistake to think that the problem can be dissolved on inductive or explanatory grounds concerning our original social acquisition of the relevant conceptuallinguistic abilities. It is true that at SK III, $\$ 43$ Sellars rejects Chisholm's account of epistemic principles as "a justification of the 'this or nothing' kind familiar to the Kantian tradition," perhaps also as involving dubious appeals to self-evident synthetic a priori principles; and that Sellars then contrasts that with his own account, according to which "these epistemic principles can be placed in a naturalistic setting and their authority construed in terms of the nature of concept formation and of the acquisition of relevant linguistic skills" (SK III, \$44). However, Sellars immediately clarifies these remarks in a way that highlights both the nature of his own Kantian conceptual analysis (as opposed to Chisholm's and the Kantian tradition's alleged 'this or nothing' appeal to self-evident synthetic principles), and thereby also displays the kind of non-empirical source of justification for epistemic principles that he thinks is required in order successfully to dispose of the threatening circle:

But surely, it will be urged, facts about learning languages and acquiring linguistic skills are themselves empirical facts; and to know these facts involves perception, memory, indeed all the epistemic activities the justification of which is at stake. Must we not conclude that any such account as I give of the principle that perceptual beliefs occurring in perceptual contexts are likely to be true is circular? It must indeed be granted that principles pertaining to the epistemic authority of perceptual and memory beliefs are not the sort of thing which could be arrived at by inductive reasoning from perceptual belief. But the best way to make

what is first and foremost 'directly evident' to us are appearances rather than, as on Sellars's own view of perceptual knowledge, physical states of affairs themselves. But what emerges from Sellars's discussion is what I have indicated in the text. 
this point is positive. We have to be in this framework to be thinking and perceiving beings at all. [. ..] But surely this makes it clear that the exploration of these principles is but part and parcel of the task of explicating the concept of a rational animal or, in $V B$ [verbal behaviorist] terms, of a language-using organism whose language is about the world in which it is used. It is only in light of this larger task that the problem of the status of epistemic principles reveals its true meaning. (SK III, $\iint 46-7$ )

What these passages from SK $\iint 45-7$ imply is that there are two sorts of answer to be given to questions concerning the justification of epistemic principles. One is that the authority of epistemic principles (such as "the principle that perceptual beliefs occurring in perceptual contexts are likely to be true") is indeed to be explained by placing them "in a naturalistic setting" of concept acquisition that accounts for why it is true - that is, how it has come to be so - that our perceptual thoughts in favorable circumstances are highly likely to be true. But that sort of theoretical or broadly inductive explanation of the reliability of our most basic conceptual capacities, crucial and indispensable as that explanation is, will indeed inevitably rely on data and hypotheses the warrant for which presupposes the general reliability of those same conceptual capacities. What Sellars takes the modified Kantian conceptual analyses to show, in addition to this, is that an independent source of warrant that is also possessed by the same set of reliable conceptual capacities - capacities which the scientific explanatory perspective thus aims to show we can intelligibly be seen to come to possess within 'a naturalistic setting' - derives from the Kantian insight that the resulting "framework" of reliable conceptual capacities can be shown, as Kant aimed to show, to be "general features any conceptual system must have in order to generate knowledge of a world to which it belongs" (KTE IX, \$41). After suggesting this more adequate Kantian naturalist account of the justification of epistemic principles, Sellars then concludes SK with the two paragraphs from EPM $\$ 38$ that were quoted above.

Strong confirmation of the above interpretation of Sellars's two-source account in SK of the warrant for general epistemic principles - that is, as based on a Kantian-style conceptual analysis and as underwritten by an intelligible sketch of, and ongoing search for, an adequate naturalistic explanation - is then provided by the fact that this is exactly what Sellars went on to propose in more detail in 1979 in his densely argued article, "More on Givenness and Explanatory Coherence" (or so, at any rate, I have contended elsewhere in relation to MGEC). ${ }^{12}$ In this late article Sellars proposes that the justification for the epistemic principles that display the warrant possessed by our particular non-inferential "IPM" judgments (i.e., our introspective, perceptual, and memory judgments) consists in their "belonging to a theory of persons as representers of themselves-in-the-world, which, although it has good explanatory power and is capable of refinement by inductive procedures, was not (and, indeed, could not have been) arrived at by inferences guided by inductive canons however broadly construed” (MGEC \$40). It turns out by the end of MGEC that such a 'Theory T', as Sellars calls it, would have to encompass two different kinds of explanation at once.

12 In O'Shea 2011: 347-54, I offered a detailed reading of MGEC along these lines in response to William A. Rottschaefer's 2011 'right wing Sellarsian' attempt to defend the sufficiency in principle of scientific explanation in Sellars's overall theory of knowledge, in contrast to my claims concerning the irreducibly Kantian aspects of Sellars's epistemology from start to finish. For another important critical exchange that explores Sellars's epistemology through to its later formulation in MGEC and other writings, see Michael Williams and Ernest Sosa in The Aristotelian Society Supplementary Volume LXXVII 2003, 'Are There Two Grades of Knowledge?', in particular Williams's 'Mythology of the Given: Sosa, Sellars and the Task of Epistemology'. Williams's own view on this matter is further developed in his 2009. 
For once again, he argues, what is needed in order to understand the justification that is possessed by the epistemic meta-principles is not only a well-confirmed empirical explanation of how, both as individuals and as a species, we could have come to possess the highly reliable conceptual capacities that are expressed in those principles. To avoid circularity, he argues, there must also be "a way in which it could be independently reasonable to accept" such principles "in spite of the fact that a ground for accepting" them "is the fact that they belong to $T$, which we suppose to be an empirically well-confirmed theory." That is, we "must carefully distinguish between having good reason to accept" such epistemic meta-principles as that, for example, our perceptual responses are highly likely to be true, "and having good reason to accept a proposed explanation of why" our perceptual responses are highly likely to be true (MGEC \84). Or more generally: "Clearly we must distinguish the question 'How did we get into the framework?' from the question 'Granted that we are in the framework, how can we justify accepting it?' In neither case, however, is the answer 'by inductive reasoning' appropriate" (MGEC \$78). In relation to the first question, Sellars suggests that

[p]resumably the question 'How did we get into the framework?' has a causal answer, a special application of evolutionary theory to the emergence of beings capable of conceptually representing the world of which they have come to be a part. (MGEC \$79).

The answer to the second question, however, "lies in the necessary connection between being in the framework of epistemic evaluation" at all - that is, in the conceptual framework that is characterized by the possession of the reliable conceptual capacities expressed in the epistemic meta-principles - "and being agents" (MGEC \$80): for philosophical analysis can show that "the concept of effective agency involves that of our IPM [e.g., perceptual] judgments being likely to be true, that is, to be correct mappings of ourselves and our circumstances" (MGEC 582). The necessary conceptual connections adverted to in these last passages, properly understood in the context of MGEC $\int \$ 66-89$, is that it is "reasonable to accept" the epistemic meta-principles because "they are elements in a conceptual framework which defines what it is to be a finite knower in a world one never made" (MGEC \$73). The upshot, Sellars concludes, is that the general perceptual reliability principle "is epistemically prior to the reasonableness of particular IPM [e.g. perceptual] judgments, whereas particular IPM judgments are epistemically prior to explanations of the likely truth of IPM judgments" (MGEC \$86).

On Sellars's account of non-inferential perceptual knowledge, then, the warrant possessed by our direct perceptions depends on the de facto (though norm-parasitic) reliability of such conceptual responses together with the standing ability of the perceiver, if called upon, to reflect on the context as one in which "no countervailing conditions obtain". The latter available inference presupposes warrant for the general principle that our perceptual responses in normal circumstances are highly likely to be true, and on Sellars's view the philosophical justification for such epistemic principles has two sides. First, it can be shown that such epistemic principles must characterize any conceptual framework that enables the cognition of objective states of affairs as such (Sellars's modified Kantian analysis); and second, evolutionary and social-developmental explanations put forward "in a naturalistic setting" must be available in principle to account for how and why our conceptual capacities have in fact come to be highly reliable in this way.

This is a defensible account of the structure of our empirical knowledge in general, and of the warrant for our non-inferential perceptual responses in particular. It also exhibits in one striking way Sellars's youthful and enduring sense that Kant's conceptual analyses will, with appropriate modifications, remain true in both the theoretical and practical domains, and this within an exhaustively scientific naturalist ontology. It is a remarkable and uniquely Kantian 
naturalist vision, although its influence has so far been felt more in each of its two distinguishable aspects, 'Kantian - or scientific naturalist?', than in its intended combined ambition.

\section{References}

Brandom, Robert (1994). Making It Explicit: Reasoning, Representing, and Discursive Commitment (Cambridge, MA and London: Harvard University Press).

Coates, Paul (2007). The Metaphysics of Perception: Wilfrid Sellars, Perceptual Consciousness and Critical Realism (London: Routledge).

Chisholm, Roderick (1966). The Theory of Knowledge (Englewood Cliffs, NJ: Prentice-Hall).

deVries, Willem A. (2009). "Getting Beyond Idealisms" (2009), in Empiricism, Perceptual Knowledge, Normativity, and Realism, ed. Willem A deVries (Oxford: Oxford University Press).

deVries, Willem A. (2005). Wilfrid Sellars (Chesham, UK: Acumen Publishing Limited).

Haag, Johannes (2012). "Some Kantian Themes in Wilfrid Sellars's Philosophy," in Centi, B. (ed.) Kant in the 20th Century (Paradigmi: Rivista di Critica Filosofica 30: 111-126.

Kant, Immanuel (1787). A Critique of Pure Reason, trans. Paul Guyer and Allen Wood (Cambridge University Press, 1997).

Landy, David (2015). Kant's Inferentialism: The Case Against Hume (London: Routledge).

McDowell, John (2016). “A Sellarsian Blind Spot,” this volume, chapter 5.

McDowell, John (1999). "Sellars's Transcendental Empiricism”, in Julian Nida-Rümelin, ed., Rationality, Realism, Revision (Proceedings of the 3rd international congress of the Society for Analytical Philosophy), Walter de Gruyter, Berlin and New York: 42-51.

Millikan, Ruth Garrett (2016). "Confessions of a Renegade Daughter,” this volume, chapter 6.

O'Shea, James R. (2012a). Kant's Critique of Pure Reason: An Introduction and Interpretation (Durham: Acumen, \& Oxford: Routledge).

O’Shea, James R. (2012b). "Prospects for a Stereoscopic Vision of our Thinking Nature: On Sellars, Brandom, and Millikan," in Humana Mente: A Journal of Philosopbical Studies (Special Issue: Between Two Images. The Manifest and the Scientific Understanding of Man, 50 Years On), Issue 21: 149-72; available online: http://www.humanamente.eu/PDF/Issue 21 Paper O'Shea.pdf

O’Shea, James R. (2011). “How to be a Kantian and a Naturalist about Human Knowledge: Sellars's Middle Way," Journal of Philosophical Research, 36: 327-59.

O'Shea, James R. (2010). "Conceptual Thinking and Nonconceptual Content: A Sellarsian Divide," in James O'Shea and Eric Rubenstein (editors), Self, Language, and World: Problems 
from Kant, Sellars, and Rosenberg (Atascadero, CA: Ridgeview Publishing Company), pp. 20528.

O'Shea, James R. (2007). Wilfrid Sellars: Naturalism with a Normative Turn (Cambridge: Polity Press).

Rosenberg, Jay F. (2005). Accessing Kant: A Relaxed Introduction to the Critique of Pure Reason. Oxford: Oxford University Press.

Rosenberg, Jay F. (1986). The Thinking Self. Atascadero, CA: Ridgeview Publ. Co. (reissue 2008).

Rosenthal, David M. (2016). “Quality Spaces, Relocation, and Grain,” this volume, chapter 8.

Rottschaefer, William A. (2011). "Why Wilfrid Sellars Is Right (and Right-Wing): Thinking With O'Shea on Sellars, Norms, and Nature" (on O'Shea 2007) and "The Middle Does Not Hold” (in reply to O'Shea 2011), Journal of Philosophical Research 36: 291-325, 361-69.

Scharp, Kevin and Robert Brandom, eds. (ISR), In the Space of Reasons: Selected Essays of Wilfrid Sellars. Cambridge, MA: Harvard University Press: 2007.

Seibt, Johanna (2016). "How To Naturalize Sensory Consciousness and Intentionality Within A Process Monism with Normativity Gradient: A Reading of Sellars," this volume, chapter 9.

Seibt, Johanna (2009). "Functions Between Reasons and Causes" in Empiricism, Perceptual Knowledge, Normativity, and Realism, ed. Willem deVries (New York, NY: Oxford University Press).

Sosa, Ernest (2007). "Mythology of the Given,” History of Philosophy Quarterly 14: 275-86.

Sellars, Wilfrid (AR) “Autobiographical Reflections: (February, 1973)," in Hector-Neri Castañeda (ed.), Action, Knowledge and Reality (Bobbs-Merrill, 1975): 277-93.

Sellars, Wilfrid (EPM) "Empiricism and the Philosophy of Mind," in Minnesota Studies in the Philosophy of Science, Vol. I, Herbert Feigl and Michael Scriven (eds.), (Minneapolis, MN: University of Minnesota Press, 1956), 253-329; reprinted in SPR and ISR.

Sellars, Wilfrid (FMPP) "Foundations for a Metaphysics of Pure Process" (The Carus Lectures) The Monist 64, 1981: 3-90. Lecture I, 'The Lever of Archimedes', is reprinted in ISR.

Sellars, Wilfrid ('I') “...this I or he or it (the thing) which thinks," the presidential address, American Philosophical Association (Eastern Division) for 1970, Proceedings of the American Philosophical Association 44 (1972): 5-31; reprinted in KTM and ISR.

Sellars, Wilfrid (KTE) "Some Remarks on Kant's Theory of Experience," Journal of Philosophy 64: 633-47, 1967; reprinted in KTM and ISR.

Sellars, Wilfrid (KTM) Kant's Transcendental Metaphysics: Sellars' Cassirer Lectures Notes and Other Essays, edited by Jeffrey F. Sicha (Atascadero, CA: Ridgeview Publ. Co., 2002).

Sellars, Wilfrid (MGEC) "More on Givenness and Explanatory Coherence," in George Pappas, ed. Justification and Knowledge (Dordrecht: Reidel, 1979): 169-82. Reprinted in Perceptual Knowledge, Jonathan Dancy ed. (Oxford: Oxford University Press, 1988): 177-191. 
Sellars, Wilfrid (MEV) "Mental Events,” Philosophical Studies 39, 1981: 325-45; reprinted in ISR.

Sellars, Wilfrid (MP) "Metaphysics and the Concept of a Person," in The Logical Way of Doing Things, edited by Karel Lambert (Yale University Press, 1969): 219-52; reprinted in KTM. (References are to paragraph numbers in KTM.)

Sellars, Wilfrid (PHM) “Phenomenalism," written in 1959 and published in SPR (1963): 60-105.

Sellars, Wilfrid (PSIM) "Philosophy and the Scientific Image of Man," in Frontiers of Science and Philosophy, Robert Colodny (ed.) (Pittsburgh, PA: University of Pittsburgh Press, 1962), 3578; reprinted in SPR pp. 1-40. (References are to SPR.)

Sellars, Wilfrid (SK) "The Structure of Knowledge: (1) Perception; (2) Minds; (3) Epistemic Principles," The Matchette Foundation Lectures for 1971 at the University of Texas, in Action, Knowledge and Reality: Studies in Honor of Wilfrid Sellars, edited by Hector-Neri Castañeda (Bobbs-Merrill, 1975): 295-347.

Sellars, Wilfrid (SM) Science and Metaphysics: Variations on Kantian Themes, The John Locke Lectures for 1965-66. (London: Routledge \& Kegan Paul, 1968; reissued by Atascadero, CA: Ridgeview, 1992).

Sellars, Wilfrid (SPR) Science, Perception and Reality (London: Routledge and Kegan Paul, 1963; reissued by Atascadero, CA: Ridgeview, 1991).

Sellars, Wilfrid (WSNDL) Wilfrid Sellars Notre Dame Lectures (1969-1986), edited with an introduction by Pedro Amaral (2009) published online by Andrew Chrucky (accessed 2013): http://www.ditext.com/amaral/wsndl.pdf

Sicha, Jeffrey F. (2002). "Introduction," in (KTM) Kant's Transcendental Metaphysics: Sellars' Cassirer Lectures Notes and Other Essays, edited by Jeffrey F. Sicha (Atascadero, CA: Ridgeview Publ. Co., 2002): 1-260 (\$S1-865).

Williams, Michael (2009). "The Tortoise and the Serpent: Sellars on the Structure of Empirical Knowledge," in Willem A. deVries, ed., Empiricism, Perceptual Knowledge, Normativity, and Realism: Essays on Wilfrid Sellars (Oxford: Oxford University Press).

Williams, Michael (2003). "Mythology of the Given: Sosa, Sellars and the Task of Epistemology," an exchange with Ernest Sosa on the topic, "Are There Two Grades of Knowledge?" in The Aristotelian Society Supplementary Volume LXXVII: 91-113 (along with Sosa's reply: 'Knowledge, Animal and Reflective: A Reply to Michael Williams”: 113-30). 